ANNALES

UNIVERSITATIS MARIAE CURIE-SKŁODOWSKA

LUBLIN - POLONIA

VOL. LXXI, 2

SECTIO AA

2016

\title{
Determination of surface free energy components of organic liquids by the thin layer wicking method
}

\author{
Lucyna Hołysz ${ }^{*}$ and Aleksandra Szcześ \\ Department Physical Chemistry - Interfacial Phenomena, \\ Faculty of Chemistry, Maria Curie Sktodowska University, \\ Maria Curie-Skłodowska Sq. 3, 20-031 Lublin, Poland \\ *email: lucyna.holysz@umcs.pl
}

\begin{abstract}
Using the layer wicking method (TLW method) the electrondonor interactions of surface free energy of the organic liquids: benzene $\left(\mathrm{C}_{6} \mathrm{H}_{6}\right)$, toluene $\left.\mathrm{C}_{6} \mathrm{H}_{5} \mathrm{CH}_{3}\right)$, and tetrahydrofuran $\left(\left(\mathrm{CH}_{2}\right)_{4} \mathrm{O}\right)$ was determined. For this purpose the penetration rate measurements of these liquids in the porous layers of silica gel and alumina were performed. The obtained values of the electron-donor parameter $\gamma_{L}^{-}$ of surface free energy of the studied organic liquids were compared with the literature data obtained by the direct measurement of the interface tensions of water/organic liquids.
\end{abstract}

\section{INTRODUCTION}

The surface free energy of solids is a very important parameter determining the interfacial properties of the solid-liquid and solid-gas interfaces. It is not possible to determine directly the surface free energy of solids, however, there are numerous indirect methods which can be applied. Thus different experiments can be performed: determining the film pressure by adsorption gas chromatography [1-3], advancing and receding contact angles of probe liquids [4-15] or free enthalpy of wetting by the thin layer wicking method [16-21]. Each method 
determining the interface properties requires some conditions e.g. a contact with the aqueous phase, an exposition to air (also implying adsorption of water vapour), as well as several limitations resulting from volatility, solubility, viscosity and thermal instability of the applied liquids. On the other hand, expression of the interfacial interactions and it mathematical description at the solid/gas and solid/liquid interfaces can be also problematic. There are several theoretical approaches to determine surface free energy. One of them is that proposed by van Oss et al. $[22,23]$ in which the energy of a phase can be expressed as a sum of apolar Lifshitz-van der Waals $\gamma_{i}^{L W}$ and polar Lewis $\gamma_{i}^{A B}$ acid-base components. The acid-base component contains two parameters: the electron-donor $\gamma_{i}^{-}$and the electron-acceptor $\gamma_{i}^{+}$, which are complementary because the electron-donor parameter can interact only with the electron-acceptor one (and vice versa). Acceptor-acceptor and donordonor interactions are impossible. Applying the Berthelot's rule $\left(\left(u_{11} u_{22}\right)^{1 / 2}=u_{12}\right)$ for the interfacial polar interactions between two phases allows their expression by the geometric mean $\gamma_{i}^{A B}=$ $2\left(\gamma_{i}^{-} \gamma_{i}^{+}\right)^{1 / 2}$. In many systems they are simply hydrogen bonds between hydrogen and oxygen atoms.

Application of suitable liquids is necessary for determination of surface free energy of solids and its components. As it was mentioned earlier, there are several limitations of application of particular liquid for determination of surface free energy and its components (volatility, viscosity, thermal stability, etc.).

In the case of contact angle measurements three probe liquids are most often used. Two of them contain different acid base parameters of surface free energy. Van Oss et al. [4] proposed to use 1-bromonaphthalene $\left(\gamma_{L}=44.4 \mathrm{~mJ} / \mathrm{m}^{2}\right)$ and diiodomethane $\left(\gamma_{L}=50.8 \mathrm{~mJ} / \mathrm{m}^{2}\right)$ for determination of Lifshitz-van der Waals component $\left(\gamma_{S}^{L W}\right)$ of surface free energy of solids, assuming that these liquids are apolar, i.e., neglecting small acid-base (acceptor-donor) interactions. For determination of $\gamma_{S}^{-}$ and $\gamma_{S}^{+}$components two bipolar liquids are needed and water is the most important of them. The other bipolar liquids with high surface tension, useful for contact angles measurements are glycerol, formamide and ethylene glycol [4]. 
The other methods applied for determination of surface free energy of powdered solid are thin layer wicking method (TLW) [12, 16-20] or thin column wicking method (TLC) [21], imbibition-drainage method (ID) $[24,25]$ and adsorption gas chromatography [1-3]. In the former methods the penetration rates of $n$-alkanes (among others, $n$-nonane and $n$-decane), diiodomethane, 1-bromonaphtalene, water and formamide are measured. $N$-nonane, $n$-decane, water and formamide can not be used in chromatographic measurements because of too high retention volumes, as well as too long time required for their complete desorption from the column. Diiodomethane and 1-bromonaphtalene can not be used either because they decompose at a boiling point. On the other hand, $n$-octane and chloroform prove to be unsuitable for wicking experiments. The evaporation rate was comparable to that of wicking, and this can be responsible for important differences in the obtained results compared to less volatile liquids.

Despite direct measurements of both the surface tension of the liquid and the interface tension of the liquid-liquid, accurate determination of the surface tension components value are difficult. The literature reports different surface tension components values for the same liquid [26-31]. So far, the problem of the surface tension components determination has not been fully resolved. However, in a one component system (e.g. a pure liquid in contact with its own vapour), the surface tension is numerically equivalent to the surface free energy $[32,33]$.

The aim of this paper was to determine the electron-donor parameter of surface free energy (surface tension) of benzene, toluene and tetrahydrofuran via the wicking experiments using the porous layers of silica gel 60 and alumina. For this purpose, first measurements of the penetration rates of apolar liquids, i.e. three $n$-alkanes: $n$-octane, $n$-nonane and $n$-decane, diiodomethane, 1-bromonaphtalene and two polar ones: water and formamide were made. From the obtained relationships $x^{2}=f(t)$ and appropriate forms of Washburn's equation the surface free energy components of these adsorbents were calculated. Next based on the obtained values of surface free energy components and the penetration rate of benzene, toluene, tetrahydrofuran their electron-donor parameters of surface free energy of these liquids were determined. 


\section{EXPERIMENTAL}

\subsection{Materials}

The commercial silica gel 60 plates (F254, Merck) and aluminum oxide 60 plates (Type E, F254, Merck) for thin layer chromatography were used. The plates for thin layer wicking experiments, $10 \times 2.5 \mathrm{~cm}$ in size, were cut off from $20 \times 220 \mathrm{~cm}$ plates. To remove water physically adsorbed on the silica and alumina surfaces, the plates were dried for $2 \mathrm{~h}$ at $150^{\circ} \mathrm{C}$ and then kept in a desiccator containing molecule sieves previously heated at $450^{\circ} \mathrm{C}$.

\subsection{Liquids}

The probe liquids: $n$-octane, $n$-nonane, $n$-decane, diiodomethane, 1-bromonaphtalene, formamide and water used for determination of surface free energy components of silica gel and alumina, as well as their origin, purity, viscosities, boiling points are listed in Table 1 together with surface tensions and their components $[5,34]$.

Table 1. Surface tensions and their components, viscosities at $20^{\circ} \mathrm{C}$ and boiling points for the probe liquids [5, 34].

\begin{tabular}{|c|c|c|c|c|c|c|c|}
\hline \multirow{2}{*}{ Liquid } & \multirow{2}{*}{ Origin and purity } & $\gamma_{L}$ & $\gamma_{L}^{L W}$ & $\gamma_{L}^{-}$ & $\gamma_{L}^{-}$ & $\eta$ & $T_{b}$ \\
\hline & & \multicolumn{4}{|c|}{$\left[\mathrm{mJ} / \mathrm{m}^{2}\right]$} & {$[\mathrm{cP}]$} & {$\left[{ }^{\circ} \mathrm{C}\right]$} \\
\hline$n$-octane & Aldrich, $>98 \%$ & 21.8 & 21.8 & 0 & 0 & 0.542 & 125 \\
\hline$n$-nonane & Fluka, $>99 \%$ & 22.9 & 22.9 & 0 & 0 & 0.714 & 151 \\
\hline n-decane & Reachim, Russia & 23.9 & 23.9 & 0 & 0 & 0.920 & 174 \\
\hline diiodomethane & POCH, p. a. & 50.8 & 50.8 & 0 & 0 & 2.821 & - \\
\hline 1-bromonaphtalene & Fluka, $>97 \%$ & 44.4 & 44.4 & 0 & 0 & 4.890 & 281 \\
\hline water & Millipore System & 72.8 & 21.8 & 25.5 & 25.5 & 1.002 & 100 \\
\hline formamide & Fluka, > 99\% & 58.0 & 39.0 & 39.6 & 2.28 & 3.783 & $193 \mathrm{R}$ \\
\hline
\end{tabular}


In Table 2 the origin and purity, viscosities and boiling points of benzene, toluene and tetrahydrofuran are presented. These liquids are used to determine the electron-donor parameter of surface free energy.

Table 2. Origin and purity of tested organic liquids, their viscosities at $20^{\circ} \mathrm{C}$ and boiling point [34].

\begin{tabular}{llcc}
\hline \multirow{2}{*}{ Liquid } & Origin and purity & $\eta$ & $T_{b}$ \\
\cline { 3 - 4 } & & {$[\mathrm{cP}]$} & {$\left[{ }^{\circ} \mathrm{C}\right]$} \\
\hline benzene & POCH, p. a. & 0.542 & 80.9 \\
toluene & POCH, p. a. & 0.714 & 110.6 \\
tetrahydrofuran & POCH, p. a. & 0.920 & 66.0 \\
\hline
\end{tabular}

\subsection{The thin layers wicking experiments}

Details of experimental procedure of the thin layers experiments were described in the paper published earlier [16-20]. The dried commercial silica gel or alumina plates were placed in a sandwich chamber DS-II5x10 type (Chromdes, Lublin, Poland - Fig. 1) applied in the thin layer chromatography [35] and the tested liquid was allowed to penetrate along the powdered layer.

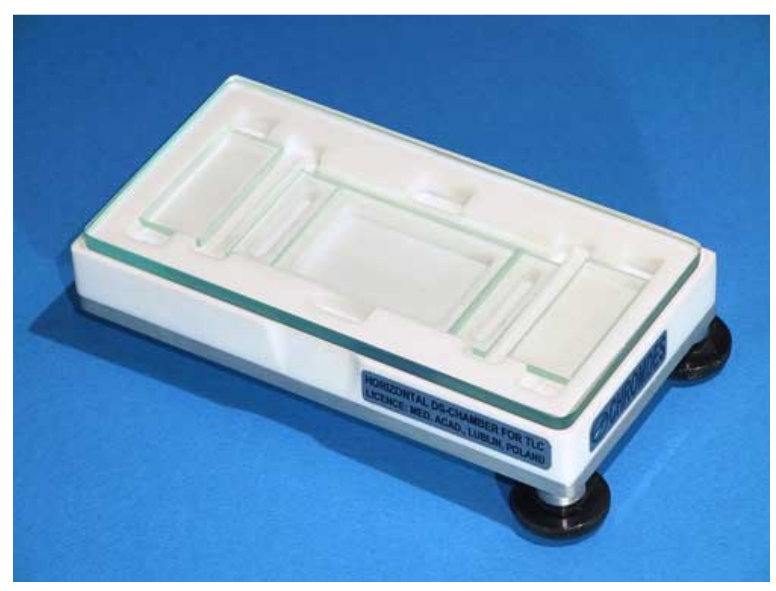

Fig. 1. A commercial sandwich chamber of DS-II-5x10 type, from Chromdes, Lublin [35]. 
The times for $1 \mathrm{~cm}$ penetrated sections were recorded. The wicking experiments were performed for bare plates and those precontacting overnight with probe liquid saturated vapour. Generally 3-5 experiments were done for each system and average values of $x^{2}=f(t)$ were plotted.

\subsection{Solid surface free energy component determination}

The thin layer wicking method was originally proposed by Giese et al. [36]. It is based on the Washburn's equation, which was applied to the liquid penetration in the porous solid layer deposited on the solid support and calculation of contact angle. The literature reports put into doubt that thus determined contact angles determined in this way were not the same as those that would be obtained on the same solid flat surface for a sessile drop [12, 37-40]. Then based on the thin layer method Chibowski and Hołysz [16-20] proposed a new form of the Washburn's equation:

$$
x^{2}=\frac{R t}{2 \eta} \Delta G
$$

where $x$ is the penetrated distance, $R$ is the apparent (effective) average radius of the bunch of capillaries in the porous layer, $\eta$ is the liquid viscosity, $t$ is the time needed for the distance $x$ to be penetrated, $\Delta G$ expresses the change in free energy during the liquid penetrating into the porous layer. Details of the theoretical background, experimental procedure and the results can be found in the literature published earlier [16-20].

The changes in $\Delta G$ depend on both the probe liquid, and the thermodynamic state of solid surface. For determination of surface free energy components there should be considered the following cases:

1. Determination of the effective radius $R$ of the porous solid layer from penetration of a completely apolar spreading liquid (no contact angle liquid e.g. n-alkane) into the porous solid layer which was precontacted earlier with the liquid saturated vapour (the subscript $p$ ): 


$$
\Delta G_{p}=\gamma_{L} \rightarrow R=\frac{2 \eta x^{2}}{t \gamma_{L}}
$$

where: $\gamma_{L}$ is the surface free energy (surface tension) of $n$-alkane which totally results from the London dispersion interactions $\left(\gamma_{L}=\gamma_{L}^{d}=\gamma_{L}^{L W}\right)$.

2. Determination of the Lifshitz-van der Waals component $\gamma_{S}^{L W}$ :

- from the penetration of completely wetting liquid into the bare surface porous layer (the surface non-contacted with the vapour, the subscript $b$ ):

$$
\begin{aligned}
\Delta G_{b}=\frac{2 \eta x^{2}}{R t} & =W_{S}=W_{A}-W_{C}=2\left(\gamma_{S}^{L W} \gamma_{L}\right)^{1 / 2}-2 \gamma_{L} \rightarrow \\
& \rightarrow \gamma_{S}^{L W}=\left(\frac{\Delta G_{b}+2 \gamma_{L}}{2\left(\gamma_{L}\right)^{1 / 2}}\right)^{2}
\end{aligned}
$$

where: $W_{S}$ is the work of spreading (the work of adhesion $W_{A}$ minus the work of cohesion $W_{C}$ ),

- from the penetration of apolar liquid (e.g. diiodomethane or 1-bromonaphtalene) into the bare and precontacted porous solid layer:

$$
\begin{aligned}
\Delta G & =\Delta G_{b}-\Delta G_{p}=2\left(\gamma_{S}^{L W} \gamma_{L}\right)^{1 / 2}-2 \gamma_{L} \rightarrow \\
& \rightarrow \gamma_{S}^{L W}=\left(\frac{\left(\Delta G_{b}-\Delta G_{p}\right)+2 \gamma_{L}}{2\left(\gamma_{L}\right)^{1 / 2}}\right)^{2}
\end{aligned}
$$

3. Determination of the electron-donor $\gamma_{S}^{-}$and the electron-acceptor $\gamma_{S}^{+}$parameters from the penetration of two polar liquids (water and formamide) into the bare and precontacted porous solid layer

$$
\begin{aligned}
& \Delta G=\Delta G_{b}-\Delta G_{p}=W_{A}-W_{C}=2\left(\gamma_{S}^{L W} \gamma_{L}^{L W}\right)^{1 / 2}+ \\
& +2\left(\gamma_{S}^{L W} \gamma_{L}^{L W}\right)^{1 / 2}+2\left(\gamma_{S}^{+} \gamma_{L}^{-}\right)^{1 / 2}+2\left(\gamma_{S}^{-} \gamma_{L}^{+}\right)^{1 / 2}-2 \gamma_{L}
\end{aligned}
$$


where $W_{A}$ is expressed according to the van Oss et al. [22, 23] approach, $\gamma_{L}^{-}$and $\gamma_{L}^{+}$are the liquid surface free energy (surface tension) electrondonor and electron-acceptor parameters, respectively. Based on the determined value of $\gamma_{S}^{L W}$ two equations of Eq. (5) type can be solved simultaneously and the solid surface free energy components can be determined.

\subsection{Electron-donor parameter of liquid surface free energy (surface tension) determination}

The electron-donor $\gamma_{L}^{-}$parameter of surface free energy of benzene, toluene, and tetrahydrofuran were determined from their penetration into the bare porous silica gel and alumina layer basing on the Eq. (6):

$$
\begin{gathered}
\Delta G_{b}=\frac{2 \eta x^{2}}{R t}=\gamma_{S}-\gamma_{L}-\gamma_{S L}=W_{S}=W_{A}-W_{C}= \\
=2\left(\gamma_{S}^{L W} \gamma_{L}\right)^{1 / 2}+2\left(\gamma_{S}^{+} \gamma_{L}^{-}\right)^{1 / 2}-2 \gamma_{L}
\end{gathered}
$$

and the Lifshitz-van der Waals component $\gamma_{S}^{L W}$, and the electron-acceptor $\gamma_{S}^{+}$parameter of the surface free energy of silica gel and alumina calculated earlier.

\section{RESULTS AND DISCUSSION}

Benzene and toluene are monopolar liquids [26-28, 30] having the electron-donor properties (Lewis base) due to the presence of electrons $\pi$ in their molecules. Benzene and its derivatives (i. e. toluene), which differ in the number of alkyl groups, do not have or have a small dipole moment and a low permittivity. These liquids do not have the ability to selfassociate, but are capable of forming hydrogen bonds with water. Polar water has an average dipole moment, high permittivity and is selfassociated by the formation of hydrogen bonding. Therefore it was also able to form hydrogen bonding with organic liquids such as benzene or toluene. In this case, the hydrogen bond results from the exothermic acidbase interactions and completely independent of the dipole moment. In 
the case of liquids, there are several methods of direct measurement of both surface free energy (surface tension) and total interfacial free energy (interfacial tension) of water-organic liquid which can be expressed as follows:

$$
\begin{gathered}
\gamma_{W L}=\left[\left(\gamma_{W}^{L W}\right)^{1 / 2}-\left(\gamma_{L}^{L W}\right)^{1 / 2}\right]^{2}+ \\
+2\left[\left(\gamma_{W}^{+} \gamma_{W}^{-}\right)^{1 / 2}+\left(\gamma_{L}^{+} \gamma_{L}^{-}\right)^{1 / 2}+\left(\gamma_{W}^{+} \gamma_{L}^{-}\right)^{1 / 2}+\left(\gamma_{L}^{+} \gamma_{W}^{-}\right)^{1 / 2}\right]
\end{gathered}
$$

Based on the above equation and the measured values of surface tension and interfacial tension of water-organic liquid [41,42], the electron-donor parameter of surface tension of organic liquid can be determined if for water at $20^{\circ} \mathrm{C} \gamma_{W}=72.8 \mathrm{~mJ} / \mathrm{m}^{2}, \gamma_{W}^{-}=\gamma_{W}^{+}=25.5 \mathrm{~mJ} / \mathrm{m}^{2}$ (Table 1) and for the monopolar liquid $\gamma_{L}=\gamma_{L}^{L W}$ (Table 3). The interfacial tensions of aromatic components (benzene and toluene) with water equal $\gamma_{W B}=35 \mathrm{~mJ} / \mathrm{m}^{2}$ and $\gamma_{W T}=36.1 \mathrm{~mJ} / \mathrm{m}^{2}$ [30].

In the literature the values of surface tensions and their electrondonor parameters for benzene and toluene can be found [26-31]. These values are presented in Table 3.

Table 3. Surface tensions and their electron-donor parameters at $20^{\circ} \mathrm{C}$ for

\begin{tabular}{|c|c|c|c|c|}
\hline \multicolumn{2}{|c|}{ Benzene } & \multicolumn{2}{|c|}{ Toluene } & \multirow{3}{*}{ References } \\
\hline$\gamma_{B}=\gamma_{B}^{L W}$ & $\gamma_{B}^{-}$ & $\gamma_{T}=\gamma_{T}^{L W}$ & $\gamma_{T}^{-}$ & \\
\hline \multicolumn{4}{|c|}{$\left[\mathrm{mJ} / \mathrm{m}^{2}\right]$} & \\
\hline 28.90 & 1.90 & 28.50 & 1.60 & [26] \\
\hline 28.90 & 2.30 & 28.30 & 2.70 & {$[27,28]$} \\
\hline 28.88 & 3.04 & - & - & [29] \\
\hline 28.85 & 2.67 & 28.50 & 2.31 & [30] \\
\hline$\gamma_{B}$ & $\gamma_{B}^{b}$ & $\gamma_{T}$ & $\gamma_{T}^{b}$ & \multirow{2}{*}{ [31] } \\
\hline 28.88 & 4.37 & 28.50 & 3.47 & \\
\hline
\end{tabular}
benzene and toluene [26-31].

According to Kloubek [31] the surface free energy of polar phase is composed of the dispersion $\left(\gamma^{d}\right)$ and acid-base $\left(\gamma^{a b}=2\left(\gamma^{a} \gamma^{b}\right)^{1 / 2}\right)$ components. The polar component is due to the dipole-dipole, dipole 
induced-dipole and hydrogen bonding. It is a function of two parameters: proton-donor, electron-acceptor or acid and $\left(\gamma^{a}\right)$ and proton-acceptor, electron-donor or basic parameter $\left(\gamma^{b}\right)$. Table 3 shows the value of basic parameter determined by Kloubek for benzene and toluene [31].

Comparing the values of surface tensions of benzene and toluene and their electron-donor parameters it can be seen that there are slight differences (Table 3). This may be due to the inaccuracy of measurement techniques, as well as that both benzene and toluene are slightly soluble in water, i.e. $0.07 \mathrm{~g}$ benzene is dissolved in $100 \mathrm{~g}$ of water at $22^{\circ} \mathrm{C}$ and $0.057 \mathrm{~g}$ of toluene in $100 \mathrm{~g}$ of water at $30^{\circ} \mathrm{C}$ [34].

Keeping this in mind, some attempts were made to determine the electron-donor parameter of surface tension of benzene, toluene and tetrahydrofuran using the thin layer wicking method where the interactions occurs at the solid-liquid interface. Hence, the preliminary studies to determine the surface free energy components of two adsorbents (silica gel and alumina) using the TLW method were carried out. For this purpose the measurements of the rate of selected liquids penetration into the silica gel and alumina thin porous layers deposited on a solid support (glass plates) were made. Then the obtained relationships were presented as $t=f\left(x^{2}\right)$ for convenience instead of $x^{2}=f(t)$, because the penetration time is actually measured.

Fig. 2 shows the penetration rate of three $n$-alkanes: $n$-octane, $n$-nonane and $n$-decane as a function of the squared distance for the plates with the porous layers of silica gel contacted earlier with the saturated vapour of these liquids ( $p$ - precontacted surface) and for bare plates ( $b$ - bare surface). As can be seen, there is a very good reproducibility of experiments up to the distance of $9 \mathrm{~cm}$. The relations were presented by linear regression, using the method of least squares.

Using the results from Fig. 2 for the precontacted surface, the effective radius of the porous silica gel layer on the glass plate was determined from Eq. (2). Then applying the average value of $R=5.019 \cdot 10^{-5} \mathrm{~cm}$ and the relationship $x^{2}=f(t)$ for the bare silica surface for these hydrocarbons, the value of Lifshitz-van der Waals components $\gamma_{S}^{L W}$ was calculated form Eq. (3). In this case it was assumed that the change of $\Delta G$ is equal to the work of spreading. 


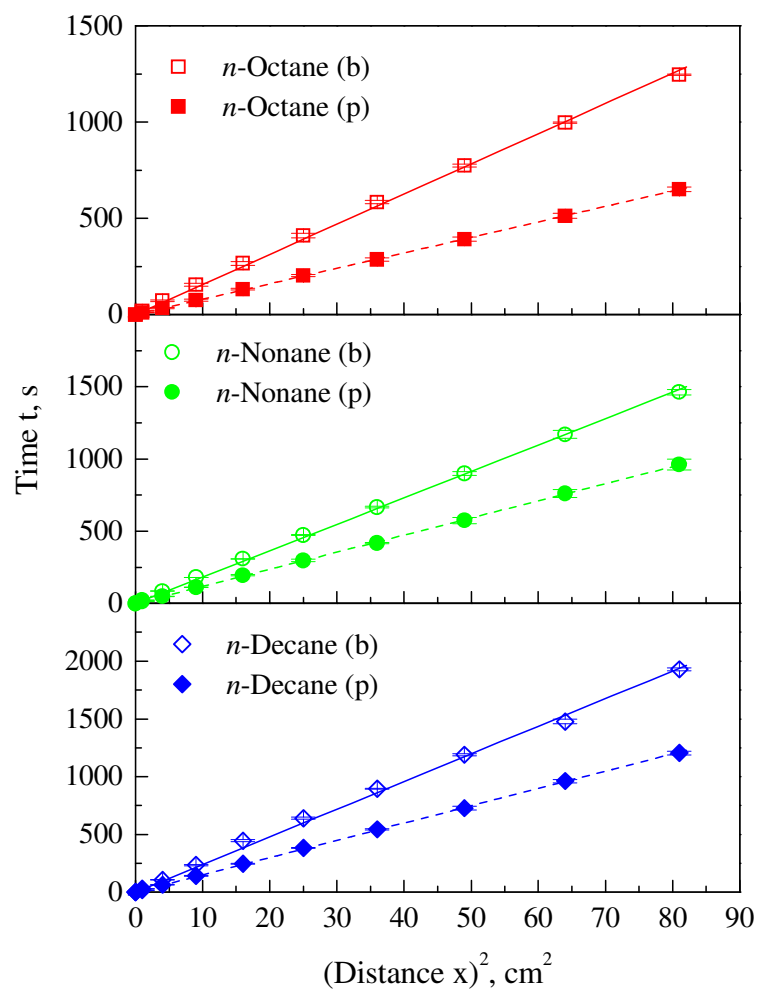

Fig. 2. Penetration time vs. the square of the distance for $n$-octane to $n$-decane on the bare (b) and precontacted (p) silica gel layers on the glass plates.

Besides two other liquids proposed by van Oss et al. [4] were used to determine $\gamma_{S}^{L W}$, namely diiodemetane and 1-bromonaphtalene. Our previous studies showed that for the liquids which form the dynamic contact angle during liquid penetration, the difference between $\Delta G_{b}$ and $\Delta G_{p}$ is equal to work of spreading $W_{S}$ [16-20, 43, 44].

Fig. 3 presents the rate of diiodemetane and 1-bromonaphtalene penetration into bare and precontacted silica gel layers. The Lifshitz-van der Waals component determined using these liquids is $\gamma_{S}^{L W}=40.7 \mathrm{~mJ} / \mathrm{m}^{2}$ and $42.1 \mathrm{~mJ} / \mathrm{m}^{2}$, respectively. After taking into account the value of $\gamma_{S}^{L W}=40.4 \mathrm{~mJ} / \mathrm{m}^{2}$ determined from three $n$-alkanes, the average value of apolar component of silica gel surface free energy was calculated and being equal to $\gamma_{S}^{L W}=41.0 \pm 0.9 \mathrm{~mJ} / \mathrm{m}^{2}$. Then the electron-donor and electron-acceptor parameters of acid-base components of surface free 
energy of silica gel were determined from the penetration of water and formamide as well as the previously determined value of $\gamma_{S}^{L W}$.

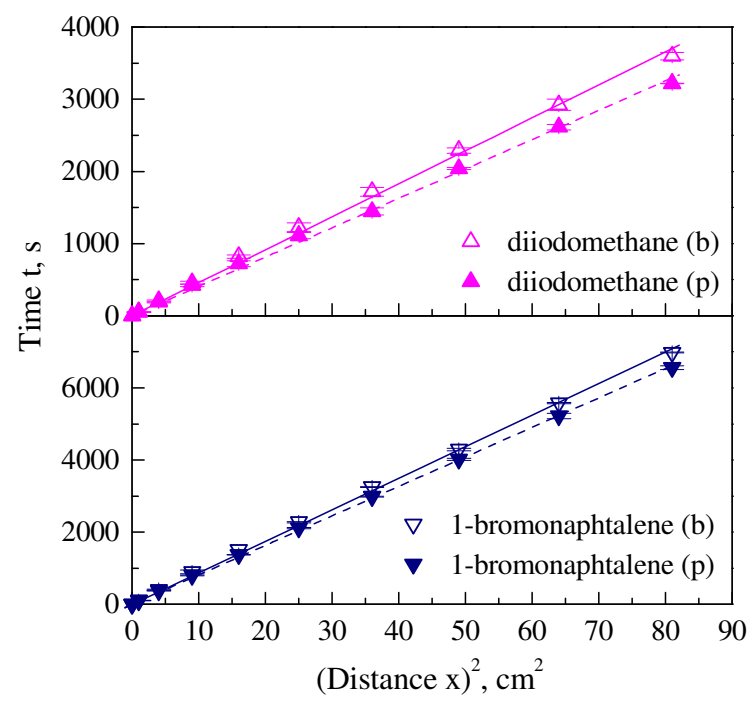

Fig. 3. Penetration time vs. the square of the distance for diiodomethane and 1-bromonaphtalene on the bare (b) and precontacted (p) silica gel layers on the glass plates.

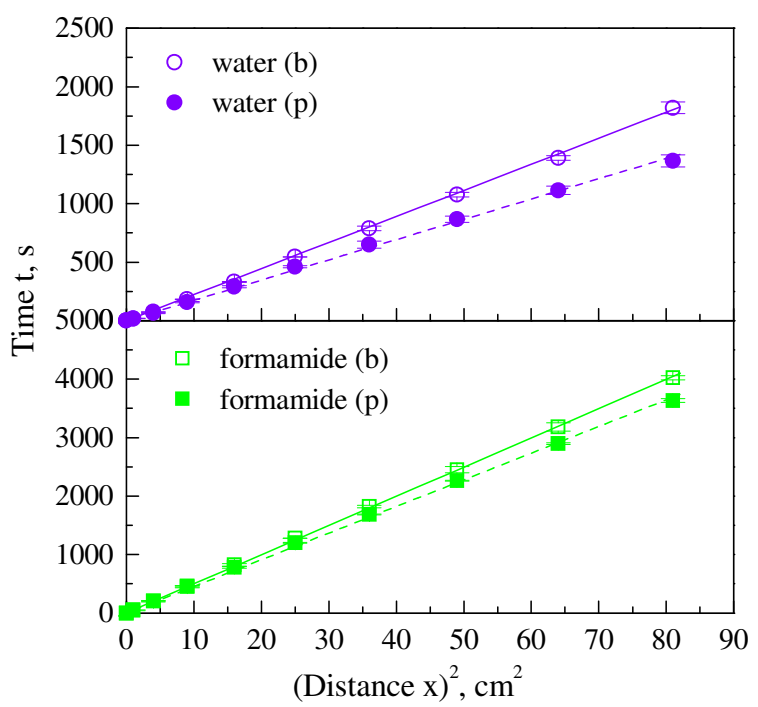

Fig. 4. Penetration time vs. the square of the distance for water and formamide on the bare (b) and precontacted (p) silica gel layers on the glass plates. 
The wicking experiments similar to those shown in Figs. 2-4 and calculations (for the whole penetration range 0-9 $\mathrm{cm}$ ) were performed for the alumina porous layers deposited on the glass plates (not reported here).

From the relationships $x^{2}=f(t)$ for $n$-alkanes, diiodomethane, 1-bromonaphtalene, the values of $\gamma_{S}^{L W}$ were calculated. Then the electrondonor and electron-acceptor parameters of the acid-base component of surface free energy of alumina were determined from the penetration of water and formamide as well as the previously determined value of $\gamma_{S}^{L W}$.

Table 4 presents the values of surface free energy components of studied silica gel and alumina determined by the thin layer wicking method.

Table 4. Effective radius of porous layers, apolar Lifshitz-van der Waals component and electron-donor and electron-acceptor parameters of acid-base component of surface free energy of silica gel and alumina.

\begin{tabular}{ccccc}
\hline \multirow{2}{*}{ Solid } & $\mathrm{R} \cdot 10^{-5}$ & $\gamma_{S}^{L W}$ & $\gamma_{S}^{-}$ & $\gamma_{S}^{+}$ \\
\cline { 2 - 5 } & {$[\mathrm{cm}]$} & & {$\left[\mathrm{mJ} / \mathrm{m}^{2}\right]$} & \\
\hline Silica gel & 5.019 & $41.0 \pm 0.9$ & 51.0 & 0.9 \\
Alumina & 5.844 & $43.6 \pm 1.8$ & 55.3 & 0.8 \\
\hline
\end{tabular}

Table 5. Literature values of surface free energy components of silica gel and alumina (in $\mathrm{mJ} / \mathrm{m}^{2}$ ).

\begin{tabular}{cccc}
\hline \multirow{2}{*}{ Method } & $\gamma_{S}^{L W}$ & $\gamma_{S}^{-}$ & $\gamma_{S}^{+}$ \\
\cline { 2 - 4 } & & Silica gel & \\
\hline TLW [16] & 41.0 & 62.4 & 0.1 \\
TCW [21] & 42.0 & 58.4 & 0.2 \\
TLW [43] & 41.2 & 51.3 & 0.7 \\
TLW [44] & 41.0 & 45.6 & 0.5 \\
TLW [45] & 41.8 & 59.4 & 0.2 \\
\hline
\end{tabular}


cont. Table 5.

\begin{tabular}{cccc}
\hline \multirow{2}{*}{ Method } & $\gamma_{S}^{L W}$ & $\gamma_{S}^{-}$ & $\gamma_{S}^{+}$ \\
\cline { 2 - 4 } & \multicolumn{3}{c}{ Silica gel } \\
\cline { 2 - 4 } TLW [46] & Alumina \\
TLW [17] & 40.0 & 54.4 & 1.2 \\
TLW [47] & 41.0 & 72.4 & 0.3 \\
TLW [48] & 43.7 & 80.5 & 0.004 \\
ID [49] & 47.1 & 72.3 & 2.4 \\
ID [24] & 41.0 & 52.9 & 0.8 \\
ID [25] & 41.7 & 56.8 & 0.6 \\
\hline
\end{tabular}

The determined surface free energy components of silica gel and alumina are consistent with those obtained by others using the same TLW method [16, 17, 43-48], thin column wicking method (TCW) [21] and imbibitiondrainage method (ID) $[24,25,49]$ (see Table 5 presenting the literature values of surface free energy components of these adsorbents).

Based on the data presented in Table 4 and the wicking experiments (Fig. 5) the electron-donor interactions of benzene, toluene and tetrahydrofuran were determined (Table 6).

Studied monopolar organic liquids, with a relatively low surface free energy (from 27.4 to $28.9 \mathrm{~mJ} / \mathrm{m}^{2}$ ), totally wet bare solid surface. Replacement of the solid-gas interface by the solid-liquid interface and a bulk liquid is accompanied by change of free energy from Eq. (6).

Values of the electron-donor parameter of the surface free energy of benzene $\left(\gamma_{B}^{-}=2.71 \mathrm{~mJ} / \mathrm{m}^{2}\right)$ and toluene $\left(\gamma_{T}^{-}=2.48 \mathrm{mN} / \mathrm{m}\right)$ determined by the thin layer wicking method are in good agreement with those in the paper by Erbil [5].

For tetrahydrofuran the reference value of basic interactions that can be found in the literature is $15.0 \mathrm{~mJ} / \mathrm{m}^{2}$ [3] and the mean value determined from two solids is $\gamma_{T h}^{-}=14.8 \pm 0.8 \mathrm{~mJ} / \mathrm{m}^{2}$. Also in this case, very good agreement was obtained using two different methods: the direct method of measuring interfacial tension (literature data) and that based on 
the indirect method of determining the components of surface free energy of the solid followed by the penetration of liquid.
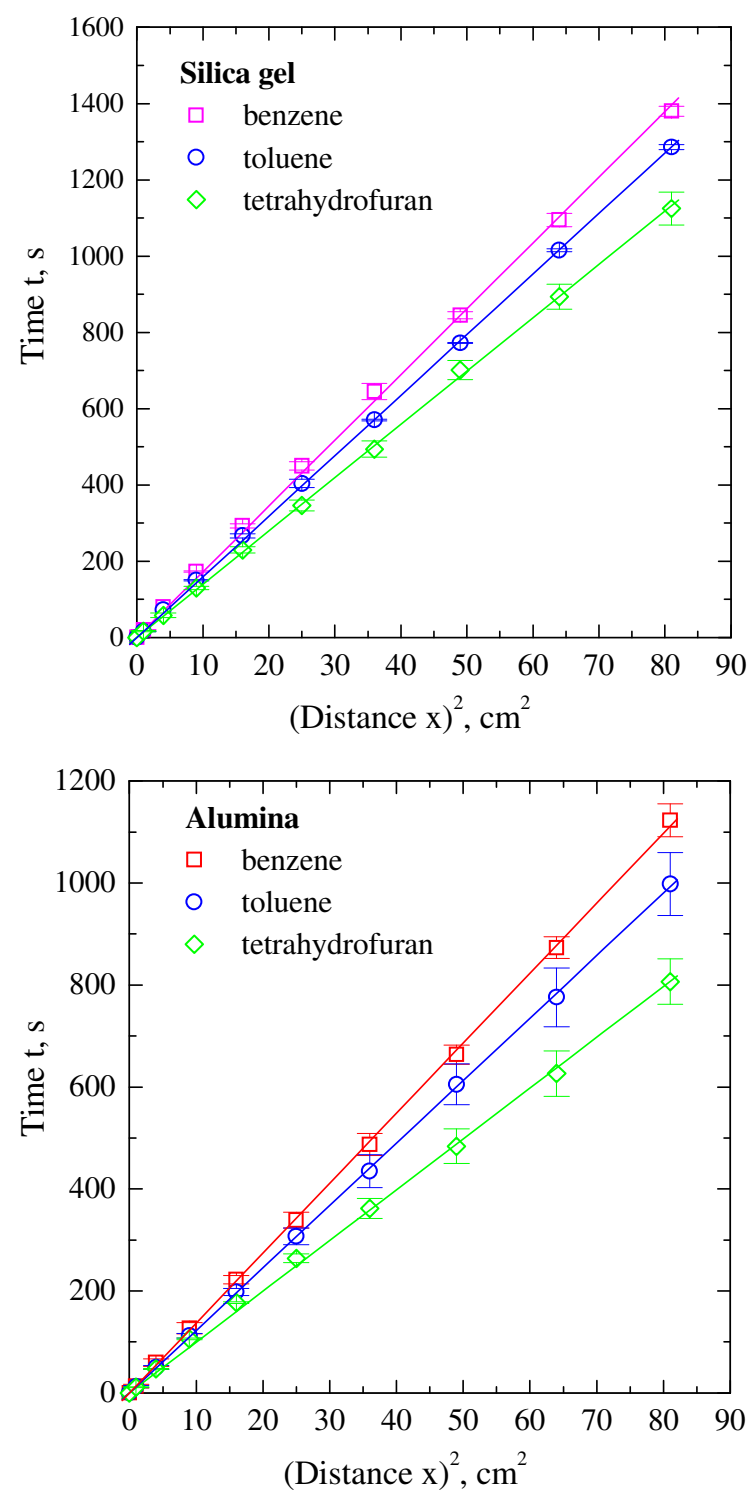

Fig. 5. Penetration time vs. the square of the distance for benzene, toluene and tetrahydrofuran on the bare silica gel and alumina layers on the glass plates. 
Table 6. Values of $\Delta G$ and electron-donor parameter of surface free energy of the studied organic liquids (in $\mathrm{mJ} / \mathrm{m}^{2}$ ).

\begin{tabular}{ccccccc}
\hline \multirow{2}{*}{ Solid } & \multicolumn{2}{c}{ Benzene } & \multicolumn{2}{c}{ Toluene } & \multicolumn{2}{c}{ Tetrahydrofuran } \\
\cline { 2 - 7 } & $\Delta G$ & $\gamma_{B}^{-}$ & $\Delta G$ & $\gamma_{T}^{-}$ & $\Delta G$ & $\gamma_{T h}^{-}$ \\
\hline Silica gel & 14.1 & 2.65 & 14.4 & 2.35 & 19.5 & 14.2 \\
\hline Alumina & 16.2 & 2.76 & 16.4 & 2.39 & 21,3 & 15.3 \\
\hline $\begin{array}{c}\text { Average } \\
\text { value }\end{array}$ & - & $2.71 \pm 0.08$ & - & $2.37 \pm 0.02$ & - & $14.8 \pm 0.8$ \\
\hline
\end{tabular}

\section{CONCLUSIONS}

The electron-donor parameter of surface free energy of benzene $\left(\mathrm{C}_{6} \mathrm{H}_{6}\right)$, toluene $\left(\mathrm{C}_{6} \mathrm{H}_{5} \mathrm{CH}_{3}\right)$, and tetrahydrofuran $\left(\left(\mathrm{CH}_{2}\right)_{4} \mathrm{O}\right)$ was determined using the thin layer wicking method. The obtained results are in a good agreement with those obtained by direct measurement of the interface tensions of water/organic liquids. From obtained results it may be concluded that the thin layer wicking method may be used as an indirect method of determining the values of the electron-donor parameter $\gamma_{L}^{-}$of pure liquids.

\section{REFERENCES}

[1] B. Biliński, A.L. Dawidowicz, Appl. Surf. Sci. 74, 277, (1994).

[2] B. Biliński, J. Colloid Interface Sci. 201, 180, (1998).

[3] B. Biliński, L. Hołysz, Powder Technol. 102, 120, (1999).

[4] C.J. van Oss, R.F. Giese and W. Wu. J. Adhesion 63, 71, (1997).

[5] C. J. van Oss, Colloids Surf. 78, 1, (1993).

[6] C.A. Ward, A.W. Neumann, J. Colloid Interface Sci. 49, 286, (1974).

[7] W. Neumann, R.J. Good, C.J. Hope, M. Sejpal, J. Colloid Interface Sci. 49, 291, (1974).

[8] H. Tavana, G. Yang, C.M. Yip, D. Appelhans. H. Zschoche, K. Grundke, M.L. Hair, A. W. Neumann, Langmuir 22, 628, (2006). 
[9] R. Tadmor, Langmuir 20, 7659, (2004).

[10] H. Chibowski, A. Ontiveros-Ortega, R. Prerea-Carpio, J. Adhesion Sci. Technol. 16, 1367, (2002).

[11] H. Radelczuk, L. Holysz, E. Chibowski, J. Adhesion Sci. Technol. 16, 1547 (2002).

[12] E. Chibowski, R. Perea-Carpio, Adv. Colloid Interface Sci. 98, 245, (2002).

[13] E. Chibowski, Adv. Colloid Interface Sci. 103, 149, (2003).

[14] E. Chibowski, Adv. Colloid Interface Sci. 113, 121, (2005).

[15] E. Chibowski, Adv. Colloid Interface Sci. 133, 51, (2007).

[16] E. Chibowski, L. Hołysz, Langmuir 8, 710, (1992).

[17] L. Hołysz, E. Chibowski, Langmuir 8, 717, (1992).

[18] E. Chibowski, F. González-Caballero, Langmuir 9, 330, (1993).

[19] E. Chibowski, L. Holysz, J. Adhesion Sci. Technol. 11, 1289, (1997).

[20] E. Chibowski, L. Hołysz, A. Szcześ, Surface Innovations 1-12 (2017), 10.1680/jsuin.16.00029

[21] L. Hołysz, Colloids Surf. A 134, 321, (1998).

[22] C. J. van Oss, R. J. Good, M. K. Chaudhury, J. Colloid Interface Sci. 111, 378, (1986).

[23] C. J. van Oss, M. K. Chaudhury, R. J. Good, Chemical Reviews 88, 927, (1988).

[24] E. Chibowski, R. Perea-Carpio, J. Colloid Interface Sci. 240, 473, (2001).

[25] M.M. Ramos-Tejada, J.D.G. Durán, A. Ontiveros-Ortega, M. Espi-nozaJimenez, R. Perea-Carpio, E. Chibowski, Colloids Surf. B 24, 309, (2002).

[26] C. J. van Oss, M. K. Chaundhury, R. J. Good, Adv. Colloid Interface Sci. 28, 35, (1987).

[27] C. J. van Oss, R. J. Good, J. Macromol. Sci. -Chem. A 26, 1183, (1989).

[28] C. J. van Oss, M. R. Chaundhury, R. J. Good, Sep. Sci. Technol. 24, 15, (1989).

[29] B. Jańczuk, W. Wójcik, A. Zdziennicka, J. Colloid Interface Sci. 157, 384, (1993).

[30] H. Y. Erbil, Langmuir 10, 286, (1994).

[31] J. Kloubek, Collect. Czech. Chem. Commun. 56, 277, (1991).

[32] S. W. Ip, J. M. Toguri, J. Mater. Sci. 29, 688, (1994). 
[33] B. Jańczuk, A. Zdziennicka, W. Wójcik, Wiadomości Chemiczne 49(56), 301, (1995).

[34] Physicochemical Constants, WNT, Warsaw, 1974.

[35] http://www.chromdes.com/pl-index.htm

[36] R. F. Giese, P. M. Constanzo, C. J. van Oss, Phys. Chem. Minerals 17, 611, (1991).

[37] L.R. Fisher, P. D. Lark, J. Colloid Interface Sci. 69, 486, (1979).

[38] Y.-W. Yang, G. Zografi, E.E. Miller, J. Colloid Interface Sci. 122, 24, (1988).

[39] Y.-W. Yang, G. Zografi, J. Pharm. Sci. 75, 719, (1986).

[40] G.E. Parsons, G. Buckton, S.M. Chatham. J. Adhesion Sci. Technol. 7, 95, (1993).

[41] L. A. Girifalco, R. J. Good, J. Phys. Chem. 61, 904, (1957).

[42] R. J. Good, E. Elbing, Ind. Eng. Chem. 62, 54, (1970).

[43] L. Hołysz, J. Mat. Sci. 33, 445, (1998).

[44] L. Hołysz, J. Mat. Sci. 35, 6081, (2000).

[45] E. W. Wiącek, Appl. Surf. Sci. 256, 7672, (2010).

[46] I. Malinowska, Habilitation Thesis, UMCS, Lublin 2001.

[47] E. Chibowski, R. Ogonowski, J. Adhesion Sci Technol. 13, 77, (1997).

[48] E. W. Wiącek, Powder Technol. 212, 332, (2011).

[49] L. Hołysz, A. Szcześ, E. Chibowski, Annales UMCS, LX,3, 34, (2005). 